\title{
Road Network Accessibility and Socio-economic Disadvantage Across Adelaide Metropolitan Area
}

\author{
Sekhar V. C. Somenahalli ${ }^{1} \cdot$ Michael A. P. Taylor $^{2} \cdot$ Susilawati Susilawati $^{3}$
}

Received: 27 September 2015/Accepted: 10 June 2016/Published online: 20 June 2016

(C) Springer International Publishing Switzerland 2016

\begin{abstract}
Transport mobility is important in defining the population's accessibility to services and facilities. Few studies have investigated the relationship between geographical accessibility of urban services for the population living in residential areas and socio-economic parameters. In this paper, the distribution of residential parcels is analyzed from a rarely explored angle - that is, its location in relation to services and facilities. The aims of this study are first to develop an index of the accessibility of various urban resources to each residential parcel in a metropolitan area of Adelaide using spatial data analysis in Geographical Information Systems and then to develop a relationship with socio-economic and land use attributes of statistical areas using ordinary least squares (OLS) and geographically weighted regression analysis. As expected the 'Distance to CBD' variable has a positive relationship with metropolitan Accessibility/Remoteness Index of Adelaide (metro-ARIA) meaning that the farther away statistical areas have lower accessibility to services. In the case of population density variable, the relationship is mostly negative except few areas
\end{abstract}

Sekhar V. C. Somenahalli

sekhar.somenahalli@unisa.edu.au

Michael A. P. Taylor

Michael.Taylor@unisa.edu.au

Susilawati Susilawati

susilawati@monash.edu

1 School of Natural and Built Environments, University of South Australia, Mawson Lakes Campus, Adelaide, SA 5095, Australia

2 School of Natural and Built Environments, University of South Australia, Adelaide, SA 5001, Australia

3 Monash University Malaysia, Jalan Lagoon Selatan, 47500 Bandar Sunway, Selangor Darul Ehsan, Malaysia in the far south, west and northern areas, which showed a positive relationship. When similar results for median family income were studied, in some of the southernmost parts of Adelaide, it showed a strong positive relationship with metro-ARIA. This research will not only provide new insight into spatial differences between metropolitan areas but also potentially help in assessing the impact of the changes in services on land use. The findings of this paper, therefore, have important implications for service provision and social infrastructure investment.

Keywords Road network accessibility · Socio-economic disadvantage $\cdot$ Metropolitan Accessibility/Remoteness Index · Adelaide $\cdot$ Geographically weighted regression analysis

\section{Introduction}

The need to meet the service requirements of the growing population is vital to the success of the Government's commitment to sustainable mobility. The motivation for this research was a belief that to properly understand the relationship between 'accessibility to urban services' and potential explanatory variables, it is important to deal with spatial data more specifically.

Concepts and methods for analyzing accessibility are essential for understanding many significant social, economic, and political issues and hence accessibility issues have increasingly become key factors in defining the quality of life and potential for development of both cities and regions. The accessibility measures, seek to define the level of opportunity and choice, taking account of both the existence of opportunities and the transport options available to reach them. Black and Conroy [1] have also argued 
that accessibility measures are a useful aid to planners and policymakers in the social evaluation of urban structure.

Transport mobility is important in defining a population's accessibility to services and facilities. Earlier studies [2-4] have focused on regional accessibility issues, while the few studies [5-8] dealing with urban resource accessibility have been limited in scope as they have dealt with only one specific urban service issue like health or public transport. However, there are few reported studies dealing with the geographical accessibility of all key urban services for the population of a metropolitan area. The aims of this study are first to develop an index of accessibility of all key urban resources to each residential parcel in a metropolitan area using spatial data analysis in the geographical information systems (GIS) and then to develop a relationship with socioeconomic and land use attributes of statistical areas using ordinary least squares (OLS) and geographically weighted regression (GWR) analysis. The paper explores the option of identifying socio-economic disadvantage areas through an 'accessibility to services' perspective. It demonstrates the depth of information that can be gleaned from local estimation as well as identifying a number of steps to improve the model's theoretical base and performance.

\section{Methodology}

This research focuses on spatial approaches to the conceptualization, measurement, and analysis of accessibility at the metropolitan level and then relates it socio-economic and land use factors. The Metropolitan Accessibility/Remoteness Index of Adelaide (Metro-ARIA) used in this study is based on the method [9] developed by National Centre for Social Applications of GIS (GISCA) at the University of Adelaide. The socio-economic indicators that this research derived include Gini coefficient, Socio-Economic Indices [10], and median family income derived from Australian Bureau of Statistics (ABS) census 2011. All variables were analysed at Census Statistical Area 1SA1 (similar to census collection districts) as the main geographic unit. The first step was to develop ordinary least squares (OLS) regression model. OLS is a global regression method that allows to model, examine and explore relationships between the dependent variable and the independent variables. After developing a properly specified OLS model, a geographically weighted regression (GWR) model was developed using the same exploratory variables. GWR builds a local regression equation for each feature in the dataset i.e. it can explore the spatial aspects of the multiple regression. The model was developed using ArcGIS 10.2 and was run on projected datasets (lambert conformal conic projection and GDA 94 datum) using an adaptive kernel type i.e. optimal number of neighbours approach for a better representation of the spatial interaction between variables.

\section{Dependent Variable}

\section{Metropolitan Accessibility/Remoteness Index of Australia (Metro-ARIA)}

Accessibility is a term generally understood to mean approximately 'ease of reaching' though the detailed definitions used may vary [11]. Accessibility is concerned with the opportunity that an individual at a given location possesses to take part in a particular activity or set of activities. The concept of the Metropolitan Accessibility and Remoteness Index of Adelaide (metro-ARIA) is still new, and so it is important to define what is meant by metro ARIA. Metro-ARIA is a geographic index which quantifies service accessibility within metropolitan areas. In this study metro-ARIA for each parcel is derived based on each residential parcel's network proximity within the metropolitan area of Adelaide. The index aims to reflect the ease or difficulty people face accessing basic services within metropolitan areas, derived from the measurement of road distances people travel to reach different services [12]. The ARIA methodology has been adapted and refined in Metro-ARIA [13]. Metro-ARIA is a continuous varying index with values ranging from zero (high accessibility) to 12 (high remoteness), and is based on road network distance measurements from the centroid of the parcel to the nearest services that include: (1) Health (Major Hospital, all hospitals and General Practice clinics), (2) shopping (central business district, major shopping centres and supermarkets), (3) education (primary schools, high schools, technical and further education institutes and universities) (4) public transport (all stops, interchanges, and bus stops with high-frequency bus services known locally as 'Go-Zone stops'), and (5) financial and postal (bank and post offices). The score range that each component contributes reflects this weighting i.e. $0-2$ or $0-3$. The five distance measurements, one to each type of service, are recorded for each residential parcel and standardized to a ratio by dividing by the weighted mean for that service. After applying a capped maximum value (of three for medical and shopping service and two for all other services) to each of the ratios, these are summed to produce the total Metro-ARIA score for each parcel (Eq. 1). Based on earlier survey report [14], the medical and shopping services have been given higher weightings when compared to other services. After calculating these indices for each parcel (refer Eq. 1; Table 1), the average metro-ARIA score for each SA1 was then calculated using the mean score of all parcels within this geographical unit i.e. metro- 
Table 1 Metro-ARIA service weighting and score range

\begin{tabular}{lll}
\hline Service type & Service facilities and weighting & Score range \\
\hline Health (Health ARIA) & (Major Hospital + All Hospital + GP)/3 & $0-3$ \\
Shopping (Shopping-ARIA) & (CBD + Major Shopping Centre + Supermarket)/3 & $0-3$ \\
Education (Education-ARIA) & Primary School + High School + TAFE + University)/6 & $0-2$ \\
Public transport (Public Transport ARIA) & (All transit stops + Go Zone (high frequency) stop + Interchange)/4.5 & $0-2$ \\
Financial and postal (Finance-ARIA) & (Bank + Post Office)/3 & $0-2$ \\
Metro-ARIA = Health-ARIA + Shopping-ARIA + Education-ARIA + Public Transport-ARIA + Finance ARIA & $0-12$ & \\
\hline
\end{tabular}

ARIA for each Statistical Area 1 (SA1) indicates the average value of the index for each parcel within each SA1.

$A R I A_{L i}=\sum_{L} \min \left\{3, \frac{x_{L i}}{\bar{x}_{L}}\right\}+\sum_{L} \min \left\{2, \frac{y_{L i}}{\bar{y}_{L}}\right\}$

$i=$ parcel location and $\mathrm{L}$ is the service type

$x_{L i}=$ distance to the nearest service from each parcel for Health and Shopping services

$y_{L i}=$ distance to the nearest service from each parcel for Education, Public Transport and 'Financial and Postal' services

$\bar{x}_{L}$ and $\bar{y}_{L}$ is the mean road distance of all parcels to the nearest category $L$ service type within the metropolitan area.

A zero value ARIA means that the location has the highest level of access to services while a value of 12 indicates the location has the lowest level of access to services (and correspondingly the highest measure of remoteness from services).

Figure 1 illustrates typical calculation of public transport ARIA for one residential parcel.

\section{The Independent Variables}

Variables to be explored were selected based on their relevance and literature review. The information for each variable is extracted at SA1 level using the Census 2011.

\section{Gini Coefficient}

The Gini coefficient is perhaps one of the most commonly used inequality statistics. Inequality is described as a property of the distribution in a population of some valued resource, such as income or wealth (which may include resources such as cattle), and even articles published by scholars in scientific journals [15]. The distribution of such quantities is typically highly skewed, with a long tail to the right. This is normally conceptualized with the Lorenz curve (Fig. 2). Take the example of income. Imagine that all income-receiving units are ranked by income from the smallest to the largest, and calculate the cumulative share of income accruing to each category of the populations

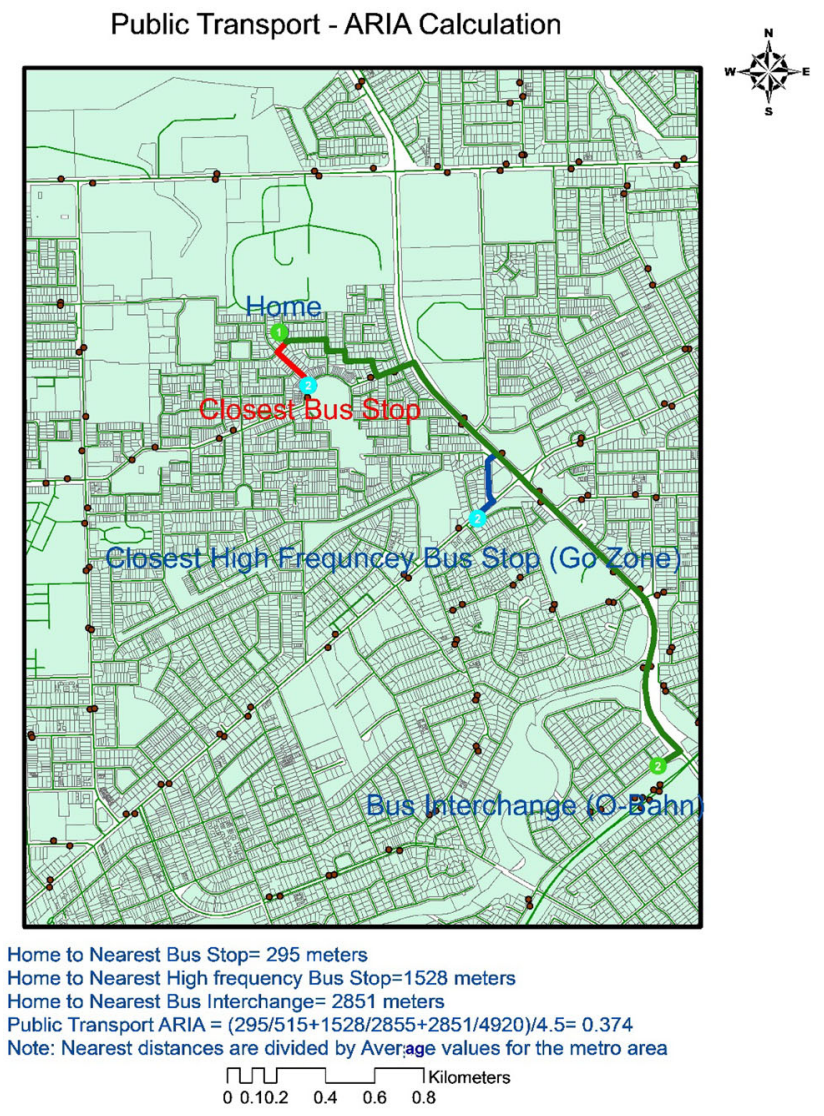

Fig. 1 Public transport ARIA calculation for one typical residential parcel

from poorest to richest. The Lorenz curve is the plot of the cumulative income share L against the cumulative population share $\mathrm{p}$.

The Gini coefficient (or "Gini index" or "Gini ratio") G is calculated from the Lorenz curve as the ratio i.e. $\mathrm{G}=$ Area A/(Area A + Area B). In Fig. 2, Lorenz curve the 45 degrees line represents a situation of perfect equality. In general, the closer the Lorenz curve is to the line of perfect equality, the less the inequality and the smaller the Gini coefficient. Algebraically the Gini coefficient is one-half of the mean of the absolute values of differences between all pairs of incomes relative to the mean income (refer Eq. 2); 
Lorenz curve \& Gini coefficient $A /(A+B)$

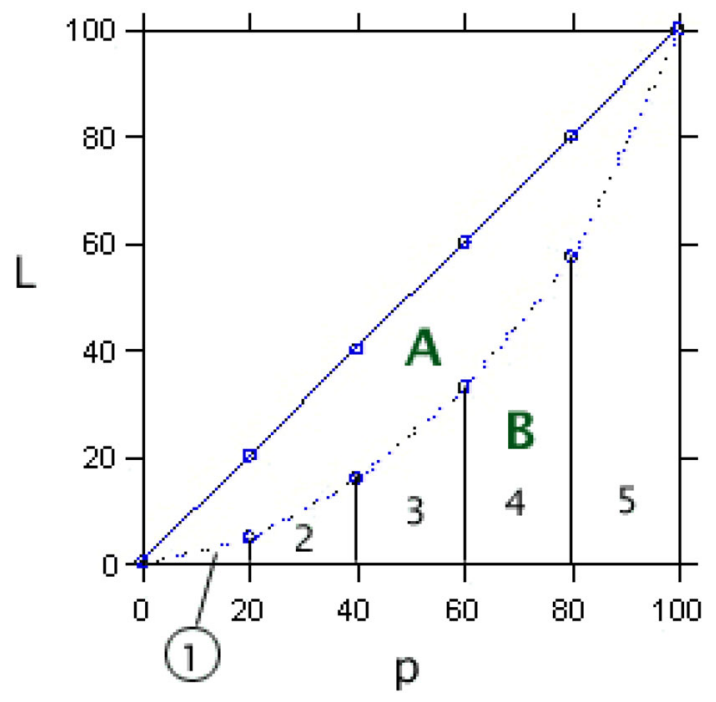

Fig. 2 Lorenz curve [15]

$G=\frac{1}{2 \Pi^{2} \bar{y}} \sum_{i=1}^{n} \sum_{j=1}^{n}\left|y_{i}-y_{j}\right|$

where $y_{i}$ and $y_{j}$ are the income of observations $i$ and $j ; \bar{y}$ is the mean income.

The Gini Coefficient is calculated for each of the 2751 Statistical Areas (SA1) in metro Adelaide using income data from the 2011 national census.

\section{Socio-Economic Indices for Area (SEIFA)}

Socio-economic indices for areas (SEIFA) is a method developed by the Australian Bureau of Statistics (ABS) to ranks areas according to relative socio-economic advantage and disadvantage. The indices are based on information from the five-yearly Census.

This study has used four SEIFA indices based on the 2011 census [16]. They are:

- The Index of Relative Socio-Economic Disadvantage (IRSD): this index is a general socio-economic index that summarizes a range of information about the economic and social conditions of people and households within an area. This index is developed by ABS and is based on 16 variables such as the percentage of the low-income households, the percentage of families with children but no job, etc. All variables in this index are indicators of disadvantage. A low score indicates relatively greater disadvantage in general.

- The Index of Relative Socio-Economic Advantage and Disadvantage (IRSAD): this index summarizes information about the economic and social conditions of people and households within an area. This index is derived using 10 variables which are indicators of advantage (the percentage of high-income households, the percentage of households paying high mortgage, etc.) and 15 variables which are indicators of disadvantage (percentage of low-income households, the percentage of households with no internet connection, etc.). A low score indicates relatively greater disadvantage and a lack of advantage in general.

- The Index of Economic Resources (IER): this index focuses on the financial aspects of relative socioeconomic advantage and disadvantage, by summarizing variables related to income and wealth. This index is derived using six variables which are indicators of advantage (the percentage of occupied private dwellings with four or more bedrooms, the percentage of occupied private dwellings paying mortgage greater than $\$ 2800$ per month, etc.) and eight variables which are indicators of disadvantage (the percentage of people with stated annual household equivalised income between $\$ 1$ and $\$ 20,799$, the percentage of occupied private dwellings with no car, etc.). A low score indicates a relative lack of access to economic resources in general

- The Index of Education and Occupation (IEO): the index of education and occupation (IEO) is designed to reflect the educational and occupational level of communities. The education variables in this index show either the level of qualification achieved or whether further education is being undertaken. This index is derived using 4 variables which are indicators of advantage (the percentage of employed people who work in a skill level 1 (highest) occupation, the percentage of people aged 15 years and over whose highest level of educational attainment is a diploma qualification, etc.) and five variables which are indicators of disadvantage [the percentage of people aged 15 years and over whose highest level of education is Year 11 or lower, the percentage of employed people who work in a skill level 5 (lowest) occupation, etc.]. A low score indicates relatively lower education and occupation status of people in the area in general.

\section{Other Variables Related to Census Data}

Other variables relating to Census data that were considered in this study are median family income, population density, dwelling unit density of those who do not own a motor vehicle, the density of seniors (65 years of age) and the density of people born outside Australia, and density of senior females. 


\section{Analysis}

Out of 2859 Statistical Areas within Adelaide Statistical Division, 2751 were chosen for further analysis as those areas with insignificant population count were omitted. When there are many potential independent variables, it is difficult to identify important variables that could contribute for properly specifying an OLS model. So using an exploratory regression data mining tool, all possible combinations of explanatory variables were tried to see which models pass all of the necessary OLS diagnostics. By evaluating all possible combinations of the candidate explanatory variables, the chances of finding the best model was improved. The exploratory regression is similar to stepwise regression; however rather than only looking for models with high adjusted $R^{2}$ values, exploratory regression looks for models that meet all of the requirements and assumptions of the OLS method [17]. However, the final selection of variables was performed using previous literature and experience.

The first step was to develop a properly specify OLS model by using exploratory regression tool i.e. a properly specified OLS model has: (1) explanatory variables where all of the coefficients are statistically significant (2) coefficients reflecting the expected, relationship between each explanatory variable and the dependent variable (3) explanatory variables that are redundant i.e. Variable Inflation factor (VIF) less than 7.5 (4) normally distributed residuals indicating the model is free from bias (the Jarque-Bera $p$ value is not statistically significant), and (5) randomly distributed over and under predictions (the spatial autocorrelation $p$ value is not statistically significant).

The following three variables performed well and also followed a uniform trend for all the statistical areas. They are (1) proximity to CBD (100\% positive, meaning as the distance to CBD increases the metro ARIA values SA1 also increase i.e. the accessibility to services will decrease) (2) population density (100\% and mostly negative, i.e. service are more accessible to CBD) (3) density of seniors i.e. aged 65 years and over (i.e. $100 \%$ negative, they are located closer to the services). Income related variables such as Gini coefficient and IER also performed well i.e. the strength of these two variables was similar to 'median family income' and 'density of dwelling units who do not own a motor vehicle'. However, as the spatial variations of these two variables are insignificant indicating a problem with local multicollinearity, they were omitted. Further thematic maps also revealed a spatial clustering of identical values and hence these variables were not specified in the OLS model. After analyzing exploratory regression results i.e. accounting for significance and removing redundant variables, the following five variables were shortlisted for OLS model specification. They are (1) proximity CBD (2) median family income (3) population density (4) density of seniors (5) density of dwellings who do not own a motor vehicle.

\section{Results}

\section{OLS Model}

The statistically significant variables ( $p$ value less than 0.05 ) are shown in Table 2. An asterisk next to the probability indicates that the coefficient is significant. Small probabilities are better (more significant) than the large probabilities. It is important to make sure that none of the explanatory variables are redundant. When two or more variables are redundant, it creates an over count indicating a bias in the model. The term for this redundancy is multicollinearity. The measurement for multicollinearity is the variance inflation factor test or VIF. The rule of thumb for interpreting VIF values is that they should be less than about 7 , but the smaller is better. Table 2 shows that all variables have VIF less than 7.5; indicating that there is no redundancy in the chosen variables.

The overall fit of the model (adjusted $R^{2}$ ) was 0.63 (Table 3) meaning that the model explained $63 \%$ of the variance of accessibility to services within Adelaide metropolitan area. The Akaike's Information Criterion AIC value can be used to measure or compare model performance. When there are several models that have the same independent variable, the best model can be assessed by looking at the lowest AIC value. Jarque-Bera statistic

Table 2 Summary of OLS results

\begin{tabular}{|c|c|c|c|c|c|}
\hline Variable & Co-efficient & Std error & t-statistic & Robust probability & VIF \\
\hline Intercept & 0.995664 & 0.137001 & 7.267589 & 0.147964 & - \\
\hline Proximity to CBD & 0.000146 & 0.000003 & 52.994675 & $0.000000 *$ & 1.48 \\
\hline Median family income & 0.001058 & 0.000059 & 18.082394 & $0.000000^{*}$ & 1.34 \\
\hline Population density & -0.000595 & 0.000044 & -13.60521 & $0.000000^{*}$ & 3.01 \\
\hline Density of dwellings who do not own motor vehicle & -0.001499 & 0.000294 & -5.104064 & $0.000000^{*}$ & 1.97 \\
\hline Density of people born outside Australia & 0.001004 & 0.000128 & 7.817715 & $0.000000^{*}$ & 4.05 \\
\hline
\end{tabular}


Table 3 OLS diagnostics

\begin{tabular}{|c|c|c|c|}
\hline & & $P$ value & Significance \\
\hline \multicolumn{4}{|l|}{ Number of observations $=2751$} \\
\hline Akaike's Information Criterion (AIC) & 8818.5074 & & $\begin{array}{l}\text { The best model can be assessed } \\
\text { by looking at the lowest AIC } \\
\text { value }\end{array}$ \\
\hline Multiple R-squared value & 0.629975 & & \\
\hline Adjusted R-squared value & 0.629301 & & \\
\hline Joint F-statistic & 934.681801 & $0.000000 *$ & \\
\hline Joint Wald statistic & 2593.76946 & $0.000000 *$ & \\
\hline Koenker (BP) statistic & 554.951132 & $0.000000 *$ & $\begin{array}{l}\text { It is statistically significant; } \\
\text { which indicates a relationship } \\
\text { between some or all of the } \\
\text { explanatory variables and } \\
\text { dependent variable are non- } \\
\text { stationary }\end{array}$ \\
\hline Jarque-Bera statistic & 941.696265 & $0.000000 *$ & $\begin{array}{l}\text { It is statistically significant, } \\
\text { hence the residuals are not } \\
\text { normally distributed }\end{array}$ \\
\hline
\end{tabular}

An asterisk next to the probability indicates that the coefficient is significant

results show that over/under predictions are not normally distributed and hence it is essential to improve this model by other approaches including GWR.

\section{Geographically Weighted Regression (GWR) Model}

A fundamental concept in geography is that nearby entities often share more similarities than entities which are far apart [18]. Spatial dependency is the co-variation of properties within geographic space: characteristics at proximal locations appear to be correlated, either positively or negatively. Earlier studies $[19,20]$ have found that regression analyses that do not compensate for spatial dependency can have unstable parameter estimates and yield unreliable significance tests. Spatial regression models capture these relationships and do not suffer from these weaknesses. GWR is expressed as shown below where the parameters $\left(\beta_{\mathrm{o}}, \beta_{\mathrm{k}}\right.$, etc. $)$ are estimated at the location $\left(\mathrm{u}_{\mathrm{i}}, \mathrm{v}_{\mathrm{i}}\right)$ using a weighted least squares method and a predicted value of $\mathrm{Y}$ [21].

$\mathrm{Y}_{\mathrm{i}}\left(\mathrm{u}_{\mathrm{i}}, \mathrm{v}_{\mathrm{i}}\right)=\beta_{\mathrm{o}}\left(\mathrm{u}_{\mathrm{i}}, \mathrm{v}_{\mathrm{i}}\right)+\sum_{\mathrm{k}} \beta_{\mathrm{k}}\left(\mathrm{u}_{\mathrm{i}}, \mathrm{v}_{\mathrm{i}}\right) \beta_{\mathrm{ik}}+\varepsilon_{\mathrm{i}}$

One of the major advantages of GWR is that tackles both spatial non-stationarity by accounting for coordinates in parameter estimates, but also spatial dependency by taking into account of geographical location in the intercepts [22]. GWR model results shown in Table 4 demonstrates the model improvements over OLS model as the adjusted R-squares values improved from $63 \%$ to nearly $85 \%$; similarly AIC values are lower when compared to OLS model.
Table 4 GWR model results

\begin{tabular}{|c|c|}
\hline $\begin{array}{l}\text { Dependent } \\
\text { variable }\end{array}$ & Metro-ARIA \\
\hline $\begin{array}{l}\text { Exploratory } \\
\text { variables }\end{array}$ & $\begin{array}{l}\text { Proximity to CBD, median fly income, } \\
\text { population density, density of dwellings that } \\
\text { don't own a motor vehicle, density of people } \\
\text { born outside Australia }\end{array}$ \\
\hline Kernel type & Adaptive \\
\hline $\begin{array}{l}\text { Bandwidth } \\
\text { method }\end{array}$ & AIC \\
\hline Sigma & 0.7711016 \\
\hline AIC & 6425.7233 \\
\hline $\mathrm{R}$-squared value & 0.851855 \\
\hline $\begin{array}{l}\text { Adjusted } \\
\text { R-squared value }\end{array}$ & 0.846951 \\
\hline
\end{tabular}

A GWR model can also help in exploring the spatial aspects of the key explanatory variables. GWR models calibrate coefficients using nearby features rather than all of the features in the dataset. So the relationships that are allowed to change across the study area. For example Fig. 3 shows the strength of two variables namely 'Distance (proximity) to CBD' and 'Population density'. As expected the 'Distance (proximity) to CBD' variable has a positive relationship with metro ARIA meaning the farther away statistical areas have lower accessibility to services. The darker areas here are the areas where the relationship between Distance to CBD and metro-ARIA is the strongest. However, some south-eastern areas have shown higher than expected strengths. The northernmost parts of Adelaide have shown low strengths due to their proximity to the town of Gawler, which is located to the immediate north of metropolitan Adelaide. In the case of the 


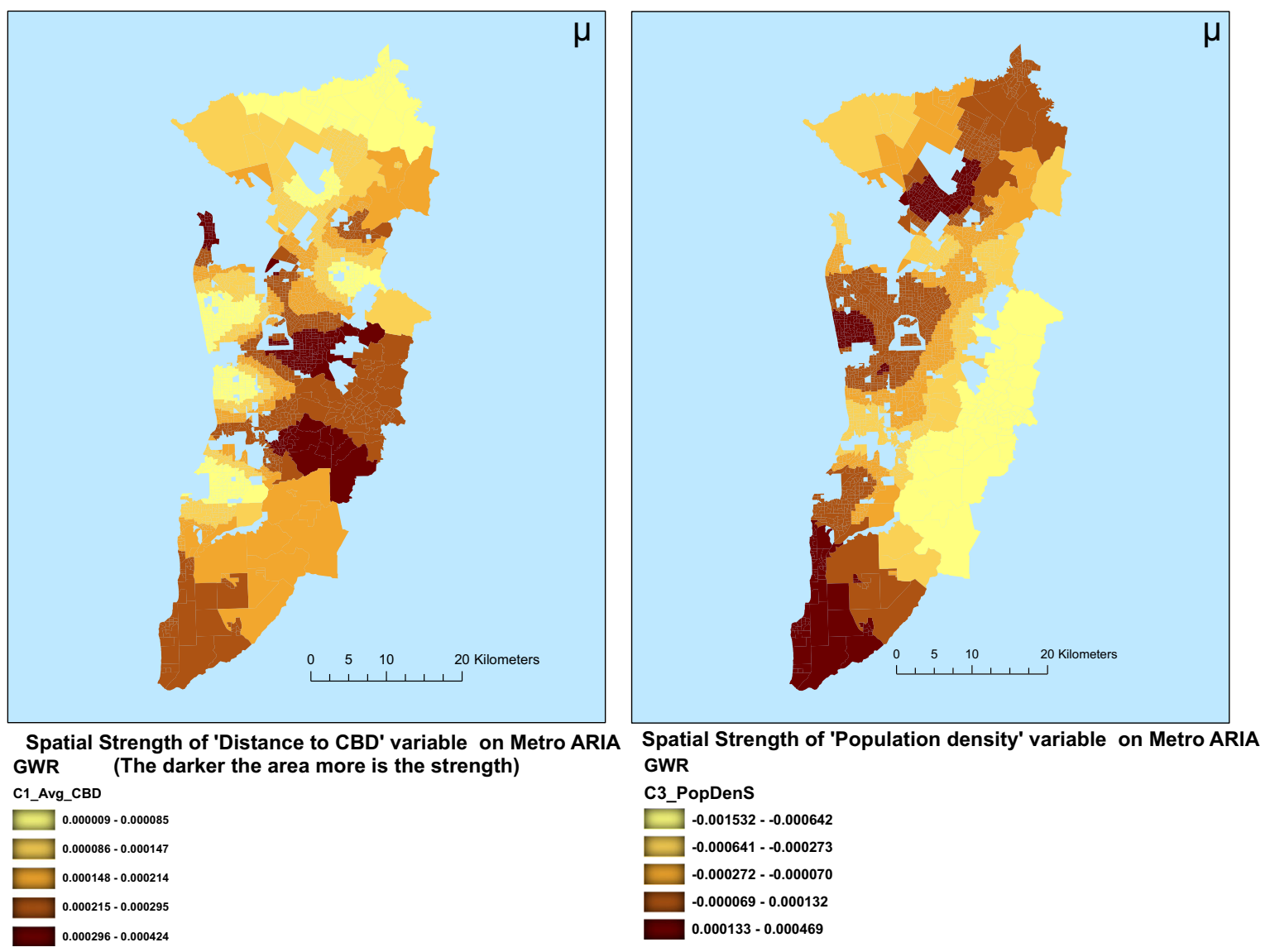

Fig. 3 Spatial strength of two explanatory variables (distance to CBD and population density) on metro-ARIA

population density variable, the relationship is mostly negative except few areas (shown in dark colour) in the far south, west and northern areas, which have shown a positive relationship. It is important to further explore these areas to identify the reasons for this mismatch. When similar result for median family income was studied, in some of the southernmost parts of Adelaide, it showed a strong positive relationship with metro- ARIA. The accessibility to services alone may not be the driving factor for residential location choice in those areas; for example, high-income families may choose live in larger accommodation in the outer suburbs.

\section{Conclusions}

The paper explored variables that are influencing accessibility/remoteness of the statistical areas with respect to key services within the metropolitan area of Adelaide. Initially, the OLS model was specified and subsequently GWR model was used for understanding the spatial strength of the variables. The OLS model was able to explain $63 \%$ of the variance of metro-ARIA variability within Adelaide.
The five key variable explained most of the variation; which include (1) proximity to CBD, (2) medium family income, (3) population density, (4) density of dwellings not owning a motor vehicle and (5) density of people born outside Australia. The GWR model increased the explanatory power of the analysis from $63 \%$ to nearly $85 \%$ of the variance. Proximity to the CBD was found to be particularly strong in influencing metro-ARIA in the inner and south-eastern parts of Adelaide. As expected population density showed a negative relationship with metro-ARIA, meaning that more people are residing closer to services with the exception of few areas in the far south, west and northern parts of Adelaide. These areas need to be examined further to understand the mismatch between population density and accessibility to services. When similar result for median family income was studied, in some of the southernmost parts of Adelaide, it showed a strong positive relationship with metro-ARIA. The other advantage of GWR models is that it can be used to make predictions and test 'what if' scenarios by providing data reflecting potential policy changes or program outcomes and see how those programs actually impact; for example, the impact of population density changes on accessibility to 
services can be predicted; which will be useful for policy makers. GWR models have also added advantage of allowing the visual interpretation of parameter results based on geography. This research will not only provide new insight into spatial differences between metropolitan areas but also potentially help in assessing the impact of the changes in services on land use. Future research should focus on the development of metro-ARIA by including travel times instead of road network distances as an impedance. Such accessibility indices could also take into consideration of multi-modal public transport systems, the pedestrian, and cycle movements.

Acknowledgments The authors acknowledge the opportunity to present the research work that forms the basis of this article at the 3rd Conference of the Transportation Research Group of India held at Kolkata (India) from 17 to 20 December 2015.

\section{References}

1. Black J, Conroy M (1977) Accessibility measures and the social evaluation of urban structure. Environ Plan A 9(9):28

2. Taylor M, Somenahalli S, D'Este G (2006) Application of accessibility based methods for vulnerability analysis of strategic road networks. Netw Spat Econ 6(3):267-291

3. Vickerman R, Spiekermann K, Wegener M (1999) Accessibility and economic development in Europe. Reg Stud 33(1):1-15

4. Somenahalli SVC, Taylor MAP (2007) Road network accessibility issues and impacts on regional Australia. J East Asia Soc Transp Stud 7(12):1-12

5. Mulley C, Tanner M (2009) The vehicle kilometres travelled (VKT) by private car: a spatial analysis using geographically weighted regression. In: 2rd Australasian Transport Research Forum (ATRF), 2009, Auckland

6. Beggs J (1996) Some empirical findings on the relationship between residential density and accessibility to job opportunities. In: 8th ARRB conference, vol 6, pp 7-15

7. Niemeier DA (1997) Accessibility: an evaluation using consumer welfare. Transportation 24:377-396
8. Apparicio P, Abdelmajid M, Riva M, Shearmur R (2008) Comparing alternative approaches to measuring the geographical accessibility of urban health services: distance types and aggregation-error issues. Int J Health Geogr 7(1):1-7

9. National Centre for Social Applications of GIS (GISCA) of University of Adelaide (2011) Metro ARIA, Working paper

10. Australian Bureau of Statistics (ABS) (1998) 1996 Census of population and housing: socio-economic indexes for areas

11. Primerano F, Taylor MAP (2005) An accessibility framework for evaluating transport policies. In: Levinson DM, Krizek KJ (eds) Access to destinations. Elsevier, Oxford, pp 325-346

12. Australia's Urban Intelligence Network (2015) Metropolitan Accessibility/Remoteness Index of Australia (Metro ARIA). http://aurin.org.au/projects/data-hubs/metro-aria/. Accessed 08 April 2015

13. Australian Population and Migration Research Centre (2015) Metro ARIA (Australian Urban Research Infrastructure Network (AURIN)). http://www.adelaide.edu.au/apmrc/research/completed/. Accessed 01 June 2016

14. Australian Institute of Health and Welfare (2013) National Social Housing Survey: detailed results 2012. Cat. no. HOU 272, AIHW, Canberra

15. Nielsen $F$ (2008) Income inequality and dualism. http://www.unc. $\mathrm{edu} / \sim$ nielsen/special/s2/s2.htm Accessed 01 June 2016

16. Australian Bureau of Statistics (ABS) (2014) What is SEIFA? http://www.abs.gov.au/ausstats/abs@.nsf/Lookup/ 2033.0.55.001main+features42011. Accessed 15 April 2015

17. ESRI (2014) Exploratory Regression (Spatial Statistics). http:// resources.arcgis.com/en/help/main/10.2/index.html\#//005p0000 0050000000. Accessed 02 May 2015

18. Charlton M, Fotheringham S, Brunsdon C (2006) Geographically weighted regression. http://eprints.ncrm.ac.uk/90/1/MethodsRe viewPaperNCRM-006.pdf Accessed 10 April 2015

19. Paez D, Currie G (2010) Key factors affecting journey to work in Melbourne using geographically weighted regression. In: 33rd Australasian Transport Research Forum, Canberra

20. Blainey S, Mulley C (2013) Using geographically weighted regression to forecast rail demand in the Sydney region. In: Australasian Transport Research Forum, Brisbane

21. Fotheringham SA, Brunsdon C, Charlton M (2002) Geographically weighted regression: the analysis of spatially varying relationships. Wiley

22. Anselin L (1999) The future of spatial analysis in the social sciences. Geogr Inf Sci 5(2):67-76 